\title{
False images top form of scientific misconduct
}

$\mathrm{F}$ amous cases of research fraud typically involve fabricated or falsified data, but the most common form of laboratory misconduct today involves scientists publishing microscopic images that don't match original data - socalled image manipulation. The practice likely accounts for more than $70 \%$ of cases handled by the United States Office of Research Integrity (ORI), according to Susan Garfinkel, director of the office's Division of Investigative Oversight.

It's the science equivalent of a news service altering a photograph to make it more convincing, says Dr. Steve Shafer, a professor of anesthesiology at Stanford University and editor of an anesthesiology journal. Manipulated images do not necessarily affect a study's findings but they are considered a form of misconduct.

In addition to institutionally imposed sanctions, researchers who manipulate images may endure a hit to their reputations. A retraction with a finding of misconduct "basically could end one's research career from the perspective of not being able to publish further," says Dr. Donald Miller, a former journal editor and an anesthesiologist at The Ottawa Hospital.

Yet scientists are sometimes unaware that changing an image is wrong. "Many laboratories consider photographs as illustrations that can be manipulated, and not as original data," one journal editor wrote to the Committee on Publication Ethics. Shafer concurs: "It's virtually never the investigator trying to get away with something. Almost always, they didn't know the rules, or a senior person didn't know the rules."

Though neither Canada nor the United States have exact numbers, image issues have increased in recent years. Many allegations of image manipulation handled by the ORI don't lead to findings, however, because the agency cannot prove the changes were intentional. (The ORI has a website explaining appropriate scientific image processing.)

In Canada, misconduct is defined more broadly, and investigators need not prove that a scientist changed an image on purpose, only that he or she breached accepted standards.

"It's important to point out that an

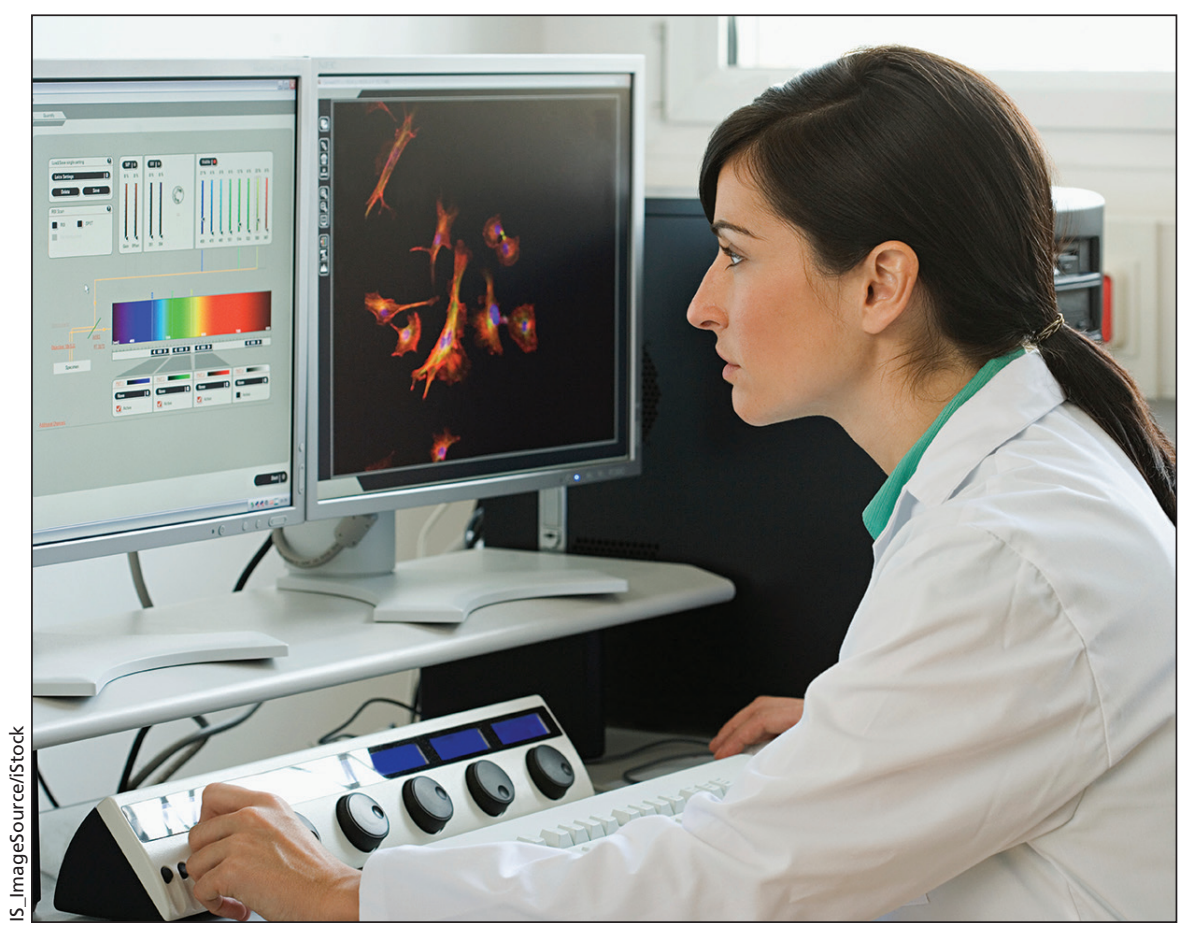

Scientists are often unaware that manipulating an image in a research paper may lead to a correction or a retraction.

honest kind of breach repeated over time can have just as damaging an impact on the public record and on research," says Susan Zimmerman, director of the federal Secretariat on Responsible Conduct of Research. The secretariat does not conduct investigations; that's up to universities and research institutes.

Several Canadian researchers have recently had to correct or retract papers due to manipulated images.

Image problems in papers by a research team at Toronto's University Health Network (UHN) were the subject of an investigation reviewed in a recent court decision in Ontario. Dr. Sylvia Asa, a cancer researcher, and endocrinologist Dr. Shereen Ezzat, retracted three papers, and editors published a notice of concern about a fourth. UHN spokesperson Gillian Howard says that in the past six years, there have been two other instances involving UHN scientists "in which images were questioned and appropriate sanctions were taken."

At McGill University in Montréal, an investigation found falsified figures in two papers by Dr. Maya Saleh, which led to corrections. University of Ottawa stem cell researcher Dr. Michael Rudnicki and coauthors retracted an article due to images that represented erroneous data. Dr. Cory Toth, former research director of the Calgary Chronic Pain Centre, retracted nine articles due to images containing manipulated data. And at the Université de Montréal, Zhiguo Wang had to retract six papers due to falsified images.

Penalties for publishing faulty images vary but can be severe. McGill provided no details on disciplinary action. The University of Ottawa made no finding of misconduct against Rudnicki and "judged ... that there was no need for sanctions," according to Catherine Paquet of the university's Office of Research Ethics and Integrity. Rudnicki leads a stem cell research program, holds a Canada Research Chair and was awarded the Order of Canada after retracting his paper.

But Toth resigned from his post and left Calgary; Wang lost his job in Montréal; and Asa and Ezzat are suspended from doing research at Toronto's UHN and both stepped down from leadership positions. - Miriam Shuchman, Toronto, Ont.

CMAJ 2016. DOI:10.1503/cmaj.109-5241 